\title{
Hard and soft tissue augmentation with occlusive titanium barriers in jaw vertical defects: a novel approach
}

\author{
Fabio Perret, Mario Aimetti, Mirko Andreasi Bassi \\ Department of Surgical Sciences, CIR Dental School, Section of Periodontology, University of Turin, Turin 10127, Italy. \\ Correspondence to: Dr. Fabio Perret, Department of Surgical Sciences, CIR Dental School, Section of Periodontology, University \\ of Turin, Via Nizza 230, Turin 10127, Italy. E-mail: info@studioperret.it
}

How to cite this article: Perret F, Aimetti M, Andreasi Bassi M. Hard and soft tissue augmentation with occlusive titanium barriers in jaw vertical defects: a novel approach. Plast Aesthet Res 2022;9:7. https://dx.doi.org/10.20517/2347-9264.2021.32

Received: 14 Apr 2021 First Decision: 27 May 2021 Revised: 11 Jun 2021 Accepted: 15 Nov 2021 Published: 21 Jan 2022

Academic Editor: Paolo Boffano Copy Editor: Xi-Jun Chen Production Editor: Xi-Jun Chen

\begin{abstract}
Aim: The aim of this study was to evaluate hard and soft tissue changes following guided bone regeneration (GBR), with occlusive titanium barriers (OTB), in the rehabilitation of partially edentulous atrophic jaws. Vertical bone gain (VBG), horizontal bone width (HBW), and flap thickness (FT) changes, observed between the first and the second surgical stages, were evaluated.
\end{abstract}

Methods: The study included 35 patients ( 9 men and 26 women; mean age $60 \pm 10.53$ years) in need of vertical bone augmentation for implant placement. Seventy implants were placed, 44 with a one-stage approach (Group A) and 26 with a two-stage approach (Group B). VBG, HBW, and FT were measured and statistically compared.

Results: VBG for implants placed in Group B was significantly higher than those placed in Group A $(P=0.006)$. The increased HBW in Group B was highly significant compared to that exhibited in Group A $(P=0.000)$. A highly significant difference was found in FT before and after the GBR in the two groups considered together, for both the upper and lower jaws $(P=0.000$ for both).

Conclusions: OTBs are reliable devices in GBR, yielding predictable results in terms of bone augmentation. In almost all cases (94.3\%), a spontaneous increase of the FT, at the second surgical phase, was observed. This could be due to the titanium surface features which increases spontaneously the thickness of soft tissues over the OTB. 
Keywords: Guided bone regeneration, occlusive titanium barriers, titanium foil, non-resorbable barriers, soft tissue increase, bone augmentation

\section{INTRODUCTION}

Alveolar bone loss, following dental extraction, can often limit the bone height and thickness available for aesthetic and prosthetic-driven implant placement ${ }^{[1,2]}$. Various techniques have been proposed and widely used to augment bone vertically and horizontally, but it is not completely clear which are the most efficient ${ }^{[3]}$. Among the different reconstructive techniques, guided bone regeneration (GBR) techniques seem to provide predictable and favorable results in long-term follow-up studies ${ }^{[4]}$. GBR was proposed by Dahlin et al. ${ }^{[5]}$ in 1988 to regenerate bone by using grafts and barriers allowing mechanical exclusion of undesirable soft tissue and, at the same time, favoring the osteogenic cellular growth into the osseous defect. In the following years, Schmid et al. ${ }^{[6]}$ and Van Steenberghe et al. ${ }^{[7]}$ demonstrated that barrier permeability is unnecessary to achieve successful GBR. Wang and Boyapati ${ }^{[8]}$ in 2006 proposed and named the "PASS" principles for successful GBR procedures: primary wound closure, angiogenesis, space maintenance, and stability of the clot. Nowadays, GBR has become a treatment option providing support for osseointegrated implants. Generally, a particulate graft composed of 50\% xenograft and 50\% autogenous bone is used, with the latter providing both the osteogenic and osteoinductive properties ${ }^{[9]}$. In vertical bone defects, the use of titanium-reinforced polytetrafluoroethylene (PTFE) barriers, in association with biomaterials, is well documented ${ }^{[9,10]}$. The use of PTFE non-resorbable barriers, compared to the resorbable barriers, can ensure an adequate space-making effect until the second-stage surgery, which usually takes place nine months after the first surgery ${ }^{[11]}$. Moreover, despite the temporary exclusion of the periosteum contact ${ }^{[12]}$, the presence of a non-resorbable barrier leads to bone volume gain, which prevents graft reabsorption ${ }^{[13]}$.

However, in the case of accidental exposure during the healing period, in most cases, the PTFE barriers must be removed within a couple of weeks, due to their contamination by oral fluids ${ }^{[14]}$.

To limit the bacteria colonization of the graft, the use of non-permeable occlusive titanium barriers (OTB) has recently been proposed as an alternative to the non-resorbable PTFE membranes in reconstructive implant surgery ${ }^{[15]}$.

An OTB is a thin pre-shaped titanium barrier which, being without openings and non-permeable, can ensure better biological protection of the graft in the case of accidental exposure. This barrier must be fixed to the residual bone with screws or pins, to ensure perfect primary stability of the particulate graft. OTBs have been used in lateral bone ridge augmentation in humans and on the rabbits' calvaria and have shown increased rates of both deposition and bone volume ${ }^{[16]}$. Furthermore, to reduce the intra-surgical time of OTB adaptation, the pre-shaping of the barrier on a printed stereolithographic model (STLM) has been proposed $^{[17,18]}$. The biocompatibility, osteoconductive properties, and mechanical properties of titanium contribute to both bone graft stabilization and space maintenance, playing an important role in achieving successful bone regeneration ${ }^{[19]}$. The lack of inflammatory response after OTB exposure was also confirmed in clinical studies concerning alveolar ridge reconstruction for implant purposes ${ }^{[20,21]}$. In this study, vertical bone augmentation via OTB was performed in a case series. Vertical bone gain (VBG), horizontal bone width (HBW) achieved, and flap thickness (FT) changes, observed between the first and second surgical phases, were evaluated from both the clinical and radiographic points of view. 


\section{METHODS}

\section{Subjects}

The study included 35 patients ( 9 men and 26 women; mean age $60 \pm 10.53$ years) in need of vertical bone augmentation for implant placement. Twenty-one were treated with simultaneous implant placement (onestage approach), while the remaining 14 underwent a delayed implant placement (two-stage approach). Seventy implants were placed (44 with a one-stage approach and 26 with a two-stages approach). All patients were systemically healthy, had never smoked, and were not taking any regular medications associated with a compromised bone healing response. Prior to treatment, informed consent was obtained from patients regarding the treatment goal and protocols. The study was performed in compliance with good clinical practice and the WMA Declaration of Helsinki for ethical principles in medical research involving human subjects (amended by the 64th WMA General Assembly, Fortaleza, Brazil, October 2013).

All patients underwent initial periodontal treatment prior to surgery. Surgical procedures were performed between February 2015 and April 2018 by the same clinician (Fabio Perret).

\section{Device preparation}

For the selected patients, cone beam computed tomography (CBCT) (Cranex 3D, Soredex - Kavo Dental, Brea, California, USA) was performed, showing a reduced thickness and height of the residual bone [Figure 1A-C]. In many cases, a lack of keratinized tissue (KT) was also evident. For each CBCT, a threedimensional STLM of the recipient site was printed to evaluate the case and pre-shape the titanium barrier. The GBRs were planned directly on each printed STLM. A $0.12 \mathrm{~mm}$ thickness OTB (Regenplate ${ }^{\otimes}$ Shape 2 and Shape 4, Bio-Micron, Sweden \& Martina, Due Carrare, Padova, Italy) was trimmed and shaped on each STLM maintaining a distance of $1.5 \mathrm{~mm}$ from the adjacent teeth, from the mental nerve, and from the mylohyoid line [Figure 1D]. The smooth side of the barrier was placed externally, while the treated rough surface was placed on the inner side of the dome, in order to obtain better blood clot adhesion ${ }^{[2,23]}$. Every sharp edge was bent inward with pliers to avoid damage to the flap. A variable number of holes were drilled with a bur ( $2 \mathrm{~mm}$ diameter) in the mesial-buccal and distal-occlusal areas of the barrier to stabilize it using fixation screws. The device was then sterilized by means of an autoclave before surgery.

\section{First phase surgery}

For all patients, antimicrobial prophylaxis was administered with amoxicillin clavulanate (Augmentin, GlaxoSmithKline, Verona, Italy), 1 g every $12 \mathrm{~h}$ for 6 days, starting $3 \mathrm{~h}$ before the operation. All surgeries were performed with the use of $4 \times$ magnification loupes (EyeZoom ${ }^{\mathrm{m}}$, Orascoptic, Madison, Wisconsin, USA). After local anesthesia, performed with articaine hydrochloride $4 \%$ plus epinephrine 1:100,000 (Citocartin, Molteni Dental, Milan, Italy), a flap design was made to ensure a primary tension-free closure. The incision varied between maxilla and mandible.

\section{Posterior mandible}

In detail, a crestal full-thickness incision was made with a 15 surgical blade, in order to equally divide the KT. A full-thickness $v s$. split-thickness flap design was chosen to maintain the whole thickness of the flap, which seems to be crucial to prevent barrier exposure, especially in vertical ridge augmentations with nonresorbable membranes ${ }^{[24,25]}$. Posteriorly the incision ended with a vestibular oblique incision $\left(45^{\circ}\right)$, at the level of the occlusal plane. In the presence of a molar, the posterior incision was marginal and distally released. Lingually, to obtain an adequate length of the flap, a marginal incision was extended mesially at least to the two adjacent teeth, avoiding vertical incisions. To obtain passivation of the lingual flap in the middle area, the superficial fibers of the mylohyoid muscle were carefully detached by a periodontal probe [Figure $2 \mathrm{~A}$ and $\mathrm{B}]$. In the distal area, the adherent tissues of the retro-molar pad were full-thickness lifted by the use of a Prichard elevator ${ }^{[25]}$. On the buccal side, the mesial extension of the flap involved one or two 

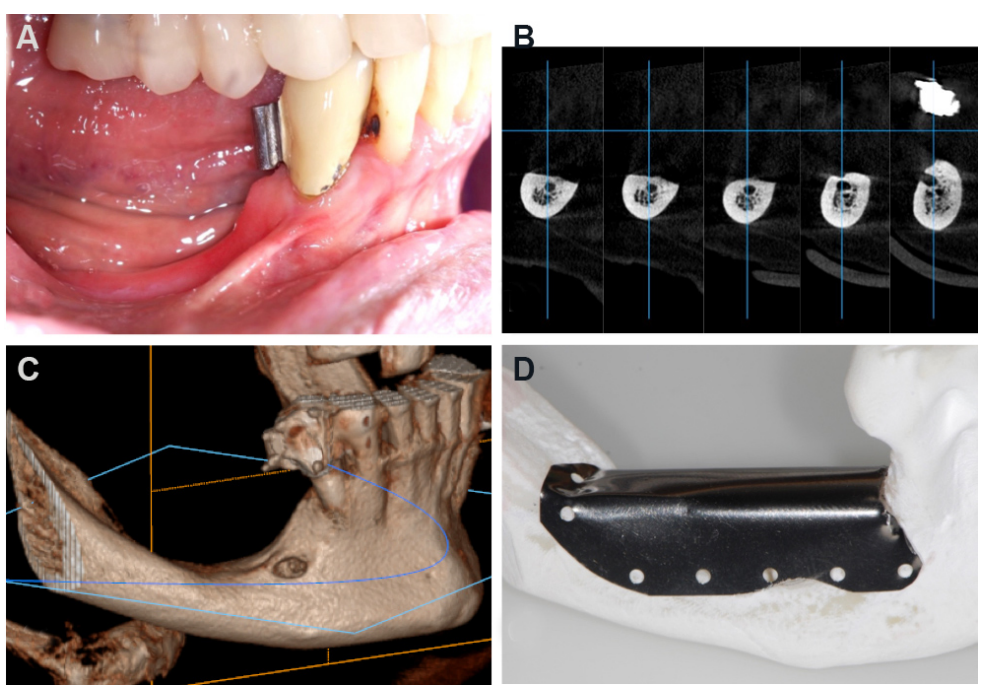

Figure 1. Two-stage guided bone regeneration procedure in a posterior atrophic mandible: (A) clinical view at the baseline; (B) CBCT cross sections; (C) CBCT rendering of the atrophic area; and (D) the titanium barrier (Regenplate ${ }^{\circledR}$ Shape 4, Bio-Micron, Sweden \& Martina, Due Carrare, Padova, Italy) prepared on the printed STLM. Two-millimeter holes were performed where the screws had to be fixed. CBCT: Cone beam computed tomography; STLM: stereolithographic model.
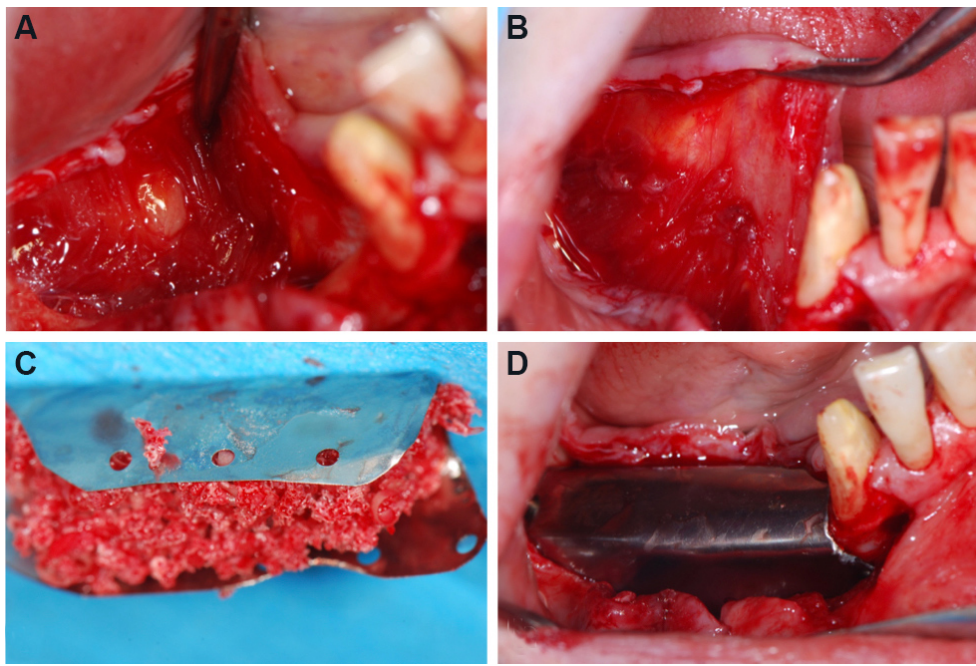

Figure 2. Surgical procedure of the case described in Figure 1: $(A)$ the superficial fibers of the mylohyoid muscle on the internal side of the lingual flap; (B) the coronal fibers of the muscle are carefully detached by a periodontal probe; (C) a 1:1 mixture of particulated autogenous bone and porcine-derived xenograft is placed into the occlusive titanium barrier previously prepared and sterilized; and (D) the device is fixed on the recipient site by means of self-tapping screws.

adjacent teeth and ended with a "hockey-stick" vertical incision with preservation of the papillae ${ }^{[26]}$. The flap was then carefully full-thickness raised to locate the mental foramen area and the neurovascular bundle. A shallow periosteum incision was made from the distal to the medial vertical incision, by using a new No. 15 blade, in order to obtain flap passivation and elongation of about $8 \mathrm{~mm}$. Then, the buccal flap was further carefully "brushed" on its internal surface until the desired elongation was achieved ${ }^{[27]}$.

\section{Maxilla}

In the upper jaw, the crestal incision was buccally shifted by about $4 \mathrm{~mm}$, in order to obtain a longer palatal flap. "Hockey stick" vertical incisions were performed following papilla preservation techniques ${ }^{[28]}$. Flap 
passivation procedures were performed only on the buccal flap until the space necessary to place the titanium barrier and the graft was obtained. When necessary, sinus lift procedures (crestal or lateral approach) were performed in the posterior maxilla during the bone augmentation procedures ${ }^{[27]}$.

\section{Implant and graft placement}

The choice of simultaneous or delayed implant placement was randomly made by the operator; however, if VBG required was $>7 \mathrm{~mm}$ the two-stage procedure was generally preferred. In the one-stage procedure, the implant sites were prepared using dedicated drills according to manufacturer instructions, and the fixtures were placed in a prosthetically driven manner, reaching a torque of at least $30 \mathrm{Ncm}$. In the two-stage procedure, the implants were placed during the second stage surgery, immediately after the OTB removal. Both in-mandible and in-maxilla perforations were not performed, because the collection of autologous bone was performed from the recipient site by using a scraper (Safescraper ${ }^{\circledast}$ TWIST, META, Reggio Emilia, Italy). The bone scraping procedure was considered sufficient to activate the regional acceleratory phenomenon, at the recipient $\operatorname{site}^{[28]}$. A 1:1 mixture of particulated autogenous bone and porcine-derived xenograft (Regeneross ${ }^{\oplus}$, Zimmer, Columbus, Ohio, USA) was placed in the inner surface of the OTB [Figure $2 \mathrm{C}$ ]. The device was, at this point, placed on the recipient site and fixed first on the lingual/palatal side, then on the distal-occlusal area, and, finally, on the buccal side using self-tapping fixation screws (0220Q-4-10; 0220Q-6-10, Cizeta, Sweden \& Martina, Due Carrare, Padova, Italy). Contact between OTB and neighboring teeth was carefully avoided, keeping the minimum distance of $1.5 \mathrm{~mm}$ [Figure 2D]. Flaps were then closed using two layers of sutures: horizontal mattress sutures were used in the first one, and then single interrupted sutures were placed to ensure an adequate closure, especially on the edges of the flaps. Vertical incisions were then closed with single sutures (Serafit ${ }^{\circ}, 6 / 0$, Serag Wiessner, Naila, Germany). Nonsteroidal analgesics and cortisone were administered. Post-surgical instructions included a soft diet for two weeks and appropriate oral hygiene, avoiding brushing and trauma at the surgical sites. Patients were instructed to rinse twice a day for about two weeks with a $0.2 \%$ chlorhexidine mouthwash. Sutures were removed about 14 days postoperatively. All patients were recalled for additional postoperative checkups and enrolled in a maintenance hygiene program.

\section{Second phase surgery}

A CBCT was performed before the second surgical stage [Figure $3 \mathrm{~A}$ and $\mathrm{B}$ ]. OTBs were removed nine months after vertical augmentations to allow proper hard tissue regeneration. A full-thickness flap was reflected to remove the titanium barrier, exposing the underlying bone crest. A thin pseudo-periosteum was always observed, even in cases with accidental exposure of the barrier [Figure $4 \mathrm{~A}$ and $\mathrm{B}$ ]. This white layer of pseudo-periosteum was left in place to protect the new regenerated hard tissue, promoting its maturation and stability through the years [Figure $4 \mathrm{C}$ and D].

In the one-stage group, the healing abutments were connected to the previously placed fixtures and left exposed to the oral cavity, while the flaps were sutured, around them, with interrupted sutures without any additional free gingival graft.

In the two-stage group, a lack of KT was often evident, even before the first surgical step [Figure 5A-D]. The implants were placed after the titanium barrier removal and connected with the healing abutments [Figure 6A and B]. In six cases of this group, immediately after implant placement, a free gingival graft was harvested and sutured over the pseudo-periosteum and around the healing abutments [Figure 6C and D], in order to reach a proper vestibule depth and a keratinized attached tissue width around the implants of at least $2 \mathrm{~mm}$ [Figure $7 \mathrm{~A}$ and $\mathrm{B}$ ]. 

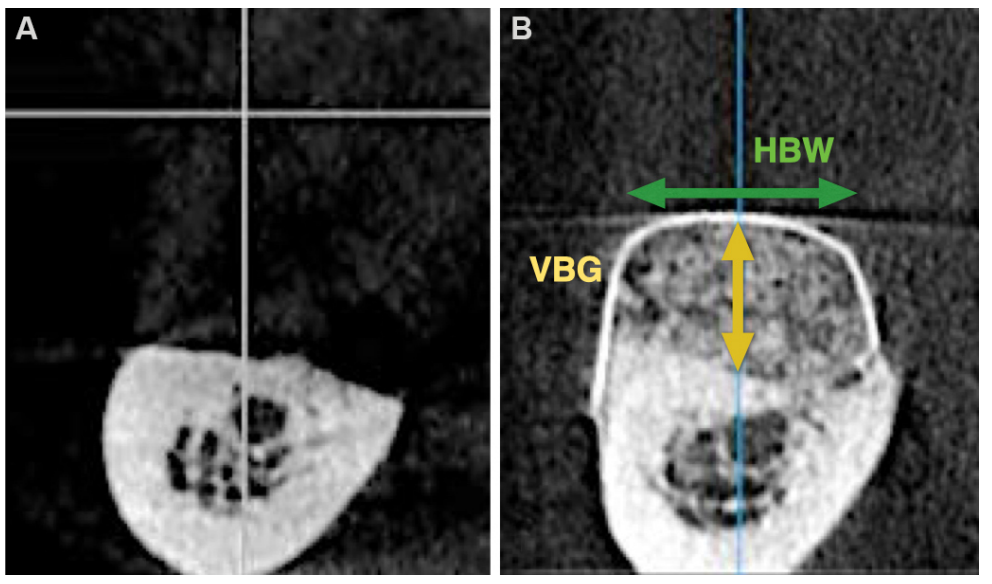

Figure 3. The evaluation of hard tissue changes of the case described in Figures 1 and 2: (A) the cone beam computed tomography cross section at the baseline; and (B) vertical bone gain and horizontal bone width are measured on CT scans, taken during the second surgical stage, by using OsiriX software). VBG: Vertical bone gain; HBW: horizontal bone width.
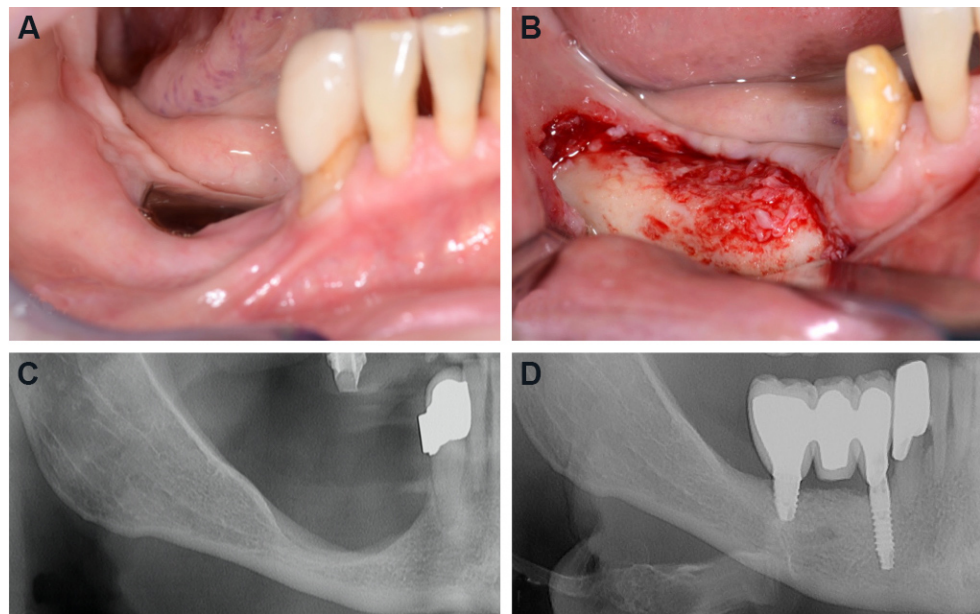

Figure 4. Continuation of the case described in Figures 1 and 2: (A) the barrier was accidentally exposed due to chewing trauma after six weeks. The occlusive titanium barrier, perfectly immobilized, was left in situ for the entire healing period of nine months. No pain or swelling was reported for the remaining 7.5 months. (B) The clinical evidence of new regenerated bone is shown. (C) The detail of the orthopantomography at the baseline is shown. (D) The vertical bone augmentation at two years of follow-up is shown.

\section{Prosthetic loading}

After three months, the healing abutment was replaced with a permanent abutment, and acrylic resin provisional restorations were placed. They were left in situ for two months, before being replaced by definitive zirconia-ceramic restorations. One- and two-year clinical and radiographic follow-up was performed after prosthetic finalization for all the cases [Figure $7 \mathrm{C}$ and $\mathrm{D}$ ] to verify the conditions of both soft and hard peri-implants tissues.

\section{Data assessment}

The following variables were statistically analyzed by an independent operator (Mirko Andreasi Bassi).

(1) Postoperative complications included OTB exposure and temporary paresthesia. 

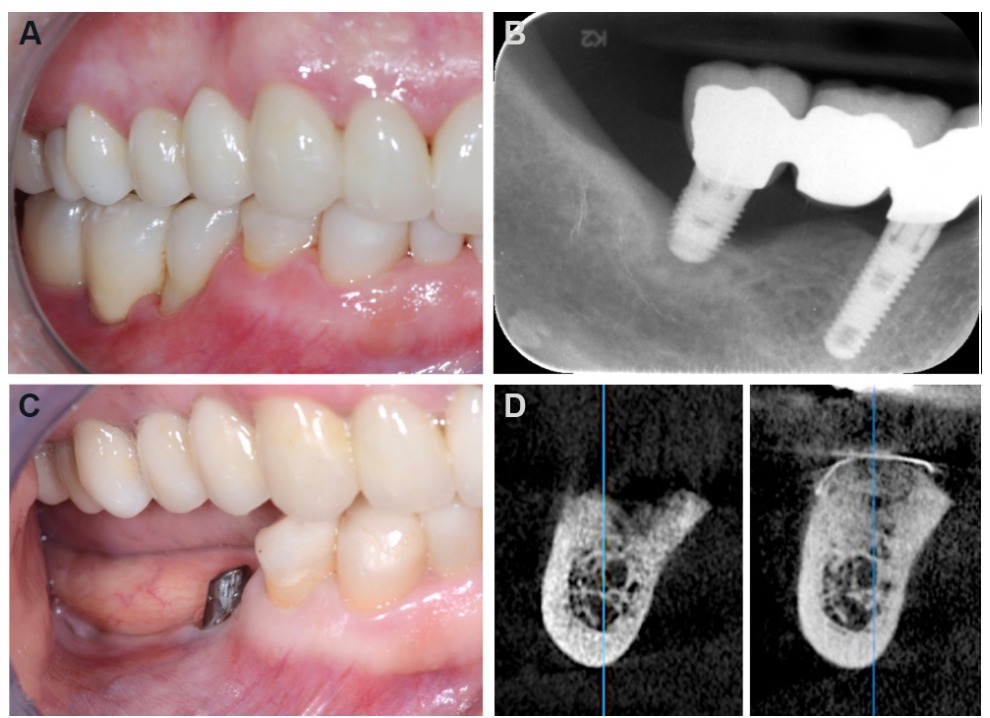

Figure 5. Free gingival graft in two-stage guided bone regeneration procedure: (A, B) clinical and radiographic view of the bone loss caused by the periimplantitis occurred on the distal implant; (C) clinical view of the healed soft tissues three months after the explantation; and (D) cone beam computed tomography cross section of the treated area, at the baseline and nine months after the occlusive titanium barrier placement (Regenplate ${ }^{\circledR}$ Shape 2, Bio-Micron, Sweden \& Martina, Due Carrare, Padova, Italy).
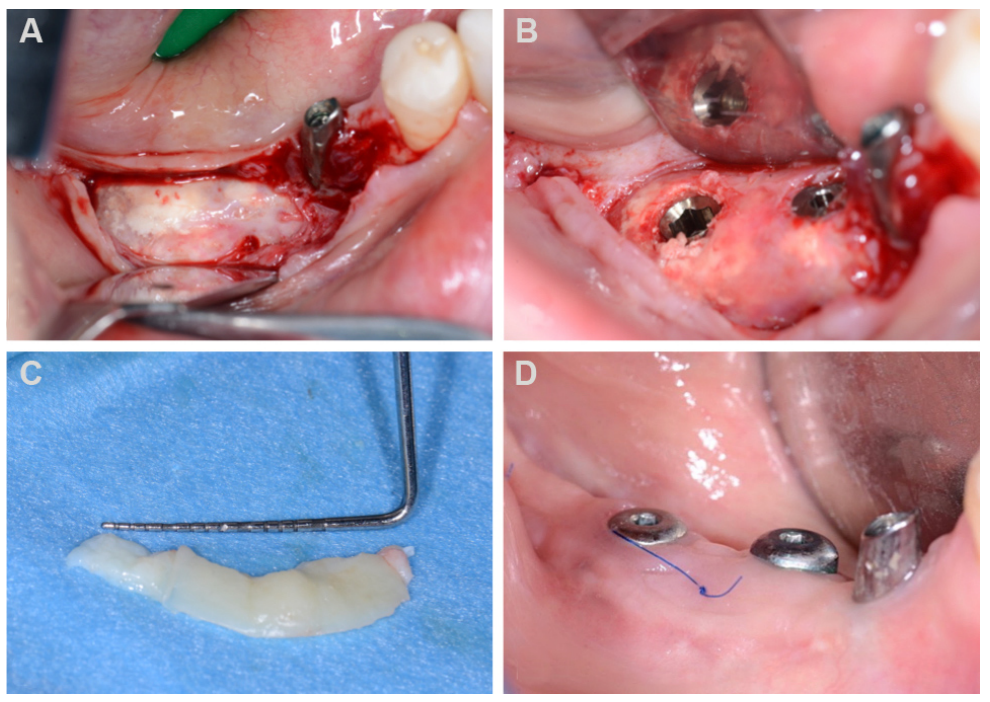

Figure 6. Continuation of the case described in Figure 5: (A) After nine months, the OTB was removed. The thin white layer of pseudoperiosteum below the OTB was left in place to protect the new regenerated tissue. (B) Two implants (diameter $3.7 \mathrm{~mm} \times 10 \mathrm{~mm}$ ) were placed in the regenerated hard tissue. (C) A free gingival graft harvested from the palate was sutured crestally to the white connective layer, buccaly to the healing abutments immediately placed. (D) An image of 21 days healing of the free gingival graft is shown. OTB: Occlusive titanium barrier.

(2) Implant failures were assessed using survival rate (SVR).

(3) Prosthetic failures included loss of the prosthesis following implant failure or prosthesis replacement for any reason. 

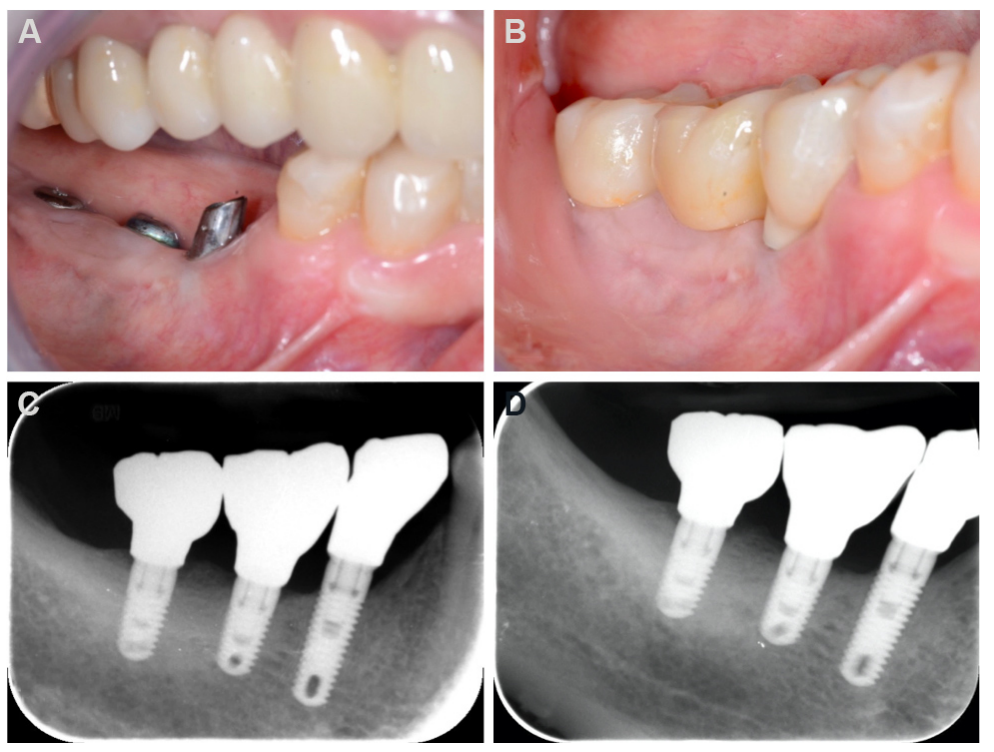

Figure 7. Continuation of the case described in Figures 5 and 6: (A) the lateral view highlights the increased height of the attached keratinized tissue, as well as the creation of the new vestibule depth; (B) the prosthetic finalization with zirconia-ceramic crowns comes five months after the mucogingival surgery; (C) the Rx after one year of follow-up; and (D) the Rx after two years of follow-up shows the crestal bone stability and the progressive mineralization of the regenerated tissue.

(4) Average vertical bone gain (AVBG): for each case, this was represented by the mean value of maximum vertical regeneration achieved, on both vestibular/buccal and lingual/palatal sides, by means of CT scans, performed during the baseline and before the second surgical stage. The measurements were carried out by means of OsiriX software (v. 3.5.1-32bit, Pixmeo, Geneva, Switzerland) [Figure 3A and B].

(5) Average horizontal bone width (AHBW): for each case, this was represented by the maximum perpendicular linear distance between the more coronal-lingual/palatal point and the more coronalbuccal/vestibular point of the regenerated hard tissue, measured on CT scans, performed during the baseline and before the second surgical stage. The measurements were carried out using the same software described above [Figure $3 \mathrm{~A}$ and $\mathrm{B}$ ].

(6) Average soft tissue thickness gain: the procedure was performed differently in the mandible and maxilla. For the mandible, the crestal incision was the same for the first and second surgical phases, thus the highest FT was measured twice with a periodontal probe (PQW, Hu-Friedy, Chicago, USA). This procedure was not performed for the maxilla because the design of the flap differed between the first and second stages. In the first stage, the crestal incision was shifted on the buccal/vestibular aspect to extend the palatal flap while, in the second stage, it was shifted on the palatal aspect to increase the thickness of KT, on the buccal/vestibular aspect. For this reason, the FT was measured with an Iwanson's Dental Gauge Caliper (CLP1, Hu-Friedy, Chicago, USA), in the area of the flap immediately projected on the implant head. If more implants were placed, only the highest FT measure was recorded. The soft tissue thickness gain (STTG) for each case was obtained by the difference between the first and second FT measurements.

\section{Data analysis}

Data were collected and statistically analyzed. Descriptive statistics of the outcome measurements, assessed in the study, are presented as means, standard deviations, and percentage rates, while STTGs, VBGs, HBWs, and FTs were statistically compared, within the groups, by means of Student's $t$-test, carried out with a confidence level of 95\% ( $\alpha=0.05)$ (Primer Biostatistics Ver. 4.02i; McGraw-Hill Comp., USA). 


\section{RESULTS}

In total, 35 subjects ( 9 males; 26 females; mean age $60 \pm 10.53$ years) were enrolled in the study. The CBCT of all the treated sites showed a reduced thickness of the residual bone. Seventy two-piece implants (ScrewVent, Zimmer, Columbus, Ohio, USA) were placed. Forty-four implants (Group A) were placed during the first stage surgery while the remaining 26 implants (Group B) during the second stage surgery. The implants were finalized with a cemented zirconia-ceramic prosthesis ( 6 crowns and 29 bridges). At the two-year follow-up, after prosthetic finalization, all implants were in place (SVR $=100 \%)$. Prosthetic failures were not observed. The clinical appearance of the soft tissues was optimal and no pathological signs were recorded upon probing. The occurrence of postoperative complications was limited to OTB exposure and was observed in two cases (5.7\%), both in the mandible, at four and six weeks after the first stage surgery. The exposures did not appear to compromise the healing and integration of the surrounding graft, and they were not associated with specific symptoms. At re-entry, the regenerated area was composed of wellvascularized hard tissue; its consistency and appearance were similar to the adjacent healthy bone.

The AVBG in the grafted sites was $4.61 \pm 2.36 \mathrm{~mm}(3.85 \pm 1.6 \mathrm{~mm}$ for Group A and $6.08 \pm 2.87 \mathrm{~mm}$ for Group B), while the AHBW was $9.41 \pm 1.15 \mathrm{~mm}(8.93 \pm 0.89 \mathrm{~mm}$ for Group A and $10.31 \pm 1.08 \mathrm{~mm}$ for Group B) [Tables 1-3]. The fixtures replaced incisors, canines, premolars, and molars in, respectively, 3\%, $3 \%, 37 \%$, and $57 \%$ of cases [Table 1 ]. In 20 cases $(57.1 \%$ ), the FT reached was $\geq 3 \mathrm{~mm}$. In six cases within Group B (17.2\%), a free gingival graft harvested from the palate area was sutured at the pseudo-periosteum over the newly regenerated tissue at the same time as implant placement and abutment connection, in order to increase the KT width and the vestibulum depth [Figures 5-7, Table 1].

The average STTG was $0.96 \pm 0.6 \mathrm{~mm}$ [Table 1]. The VBG for implants placed in the second stage surgery (Group B) was significantly higher than those placed in the first stage (Group A) $(P=0.006)$ [Tables 2 and 3]. The greater value of HBW reached in Group B was highly significant compared to that exhibited by Group A $(P=0.000)$ [Tables 2 and 3]. No differences were found between Groups A and B regarding the FTs during both the first stage $(P=0.763)$ and second stage surgeries $(P=0.849)$ [Tables 2 and 3]. No differences were found between Groups A and B concerning the STTGs in the upper and lower jaws $(P=0.113$ for both). A highly significant difference was found for the FT before and after the GBR for all implants $(P=0.000)$. For Group B, this difference was highly significant as well $(P=0.000)$, while it was only significant for Group A $(P=0.017)$ [Tables 1-3]. A highly significant difference was found concerning the FT before and after the GBR in the two groups considered together, for both the upper and lower jaws ( $P=$ 0.000 for both) [Table 1]. No differences were found concerning the STTGs between male and female patients considering the implants as a whole $(P=0.554)$ [Table 1].

\section{DISCUSSION}

The GBR is better documented through long-term follow-up studies compared to other bone augmentation techniques. Since the 1980s, a titanium mesh with different size perforations has been used as a device for bone augmentation to enable dental implant placement. Although the presence of these perforations enhances the blood supply from the flap and the bone graft, they may favor soft-tissue growth into the defect, reducing the volume of the hard tissue regenerated and making the barrier difficult to remove during the second surgery ${ }^{[20]}$. In vertical bone defects, the use of titanium-reinforced PTFE barriers, in association with biomaterials, is also well documented. However, due to its structural microporosity, PTFE is subject to rapid bacterial contamination in the case of exposure to oral fluids. This phenomenon is evident, for example, in PTFE sutures, which tend to change color a few days after surgery and generally must therefore be removed within a couple of weeks ${ }^{[21]}$. 
Table 1. The parameters evaluated in the study

\begin{tabular}{|c|c|c|c|c|c|c|c|c|c|c|}
\hline \multicolumn{5}{|c|}{ Implants Groups A and B } & \multirow[b]{2}{*}{$\begin{array}{l}\text { Age } \\
\text { (years) }\end{array}$} & \multirow[b]{2}{*}{$\begin{array}{l}\text { VBG } \\
(\mathrm{mm})\end{array}$} & \multirow[b]{2}{*}{$\begin{array}{l}\text { HBW } \\
(\mathrm{mm})\end{array}$} & \multirow[b]{2}{*}{$\begin{array}{l}\text { FTB } \\
(\mathrm{mm})\end{array}$} & \multirow[b]{2}{*}{$\begin{array}{l}\text { FTA } \\
(\mathrm{mm})\end{array}$} & \multirow[b]{2}{*}{$\begin{array}{l}\text { STTG } \\
(\mathrm{mm})\end{array}$} \\
\hline Patients & $\begin{array}{l}\text { Implants } \\
\text { A }\end{array}$ & $\begin{array}{l}\text { Implants } \\
\text { B }\end{array}$ & Sex & Site & & & & & & \\
\hline 1 & 3 & & $\mathrm{~F}$ & $\begin{array}{l}44-45- \\
46\end{array}$ & 72 & 5.5 & 9.8 & 1.5 & 2 & 0.5 \\
\hline 2 & & 3 & $\mathrm{~F}$ & $34-36-37$ & 72 & 5 & 10.5 & 1.5 & 2.5 & 1 \\
\hline 3 & 3 & & M & $45-46-47$ & 51 & 5.5 & 10.5 & 2 & 2 & 0 \\
\hline 4 & 2 & & $\mathrm{~F}$ & $24-26$ & 54 & 7 & 9.3 & 2 & 3 & 1 \\
\hline 5 & 2 & & $\mathrm{~F}$ & $46-47$ & 67 & 6.5 & 8.8 & 1.5 & 2 & 0.5 \\
\hline 6 & 3 & & $\mathrm{~F}$ & $\begin{array}{l}44-45- \\
46\end{array}$ & 60 & 7 & 7.8 & 1.5 & 2 & 0.5 \\
\hline 7 & & 3 & $\mathrm{~F}$ & $\begin{array}{l}44-46- \\
47\end{array}$ & 77 & 3 & 9.5 & 1 & 2.5 & 1.5 \\
\hline 8 & 2 & & $\mathrm{~F}$ & $35-36$ & 48 & 4 & 8 & 2.5 & 3 & 0.5 \\
\hline 9 & 1 & & $\mathrm{~F}$ & 46 & 48 & 3 & 7.5 & 1.5 & 1.5 & 0.5 \\
\hline 10 & & 2 & $\mathrm{~F}$ & $36-37$ & 67 & 4 & 10.5 & 1.5 & 2 & 0.5 \\
\hline 11 & & 2 & M & $24-26$ & 76 & 11 & 9.3 & 2.5 & 3.5 & 1 \\
\hline 12 & 2 & & $\mathrm{~F}$ & $25-26$ & 67 & 4 & 8 & 2 & 3 & 1 \\
\hline 13 & & 2 & $\mathrm{~F}$ & $46-47$ & 74 & 6.5 & 11.5 & 2 & 4 & 2 \\
\hline 14 & & 2 & $\mathrm{~F}$ & $36-37$ & 74 & 6.5 & 11.3 & 1.5 & 3.5 & 2 \\
\hline 15 & & 2 & $\mathrm{~F}$ & $44-46$ & 72 & 9 & 11.5 & 2 & 2 & 0 \\
\hline 16 & & 2 & $\mathrm{~F}$ & $34-36$ & 72 & 11 & 11.8 & 2 & 3 & 1 \\
\hline 17 & 1 & & $\mathrm{~F}$ & 46 & 40 & 5 & 10.5 & 2.5 & 3 & 0.5 \\
\hline 18 & & 2 & $\mathrm{~F}$ & 16 & 60 & 4 & 10.5 & 2 & 3.5 & 1.5 \\
\hline 19 & 2 & & $\mathrm{~F}$ & $13-23$ & 68 & 4 & 8.8 & 1.5 & 3.5 & 2 \\
\hline 20 & 1 & & $\mathrm{~F}$ & 34 & 59 & 3 & 8.5 & 2 & 3 & 1 \\
\hline 21 & 2 & & $\mathrm{~F}$ & $46-47$ & 65 & 2 & 9.5 & 2 & 3 & 1 \\
\hline 22 & 2 & & M & $42-31$ & 58 & 2 & 8.5 & 1.5 & 3 & 1.5 \\
\hline 23 & & 2 & $\mathrm{~F}$ & $46-47$ & 42 & 3 & 9.5 & 2 & 3 & 1 \\
\hline 24 & 1 & & M & 47 & 52 & 5 & 9.5 & 1.5 & 3 & 1.5 \\
\hline 25 & 2 & & M & $14-16$ & 61 & 2 & 10 & 2 & 3.5 & 1.5 \\
\hline 26 & & 2 & $\mathrm{~F}$ & $14-15$ & 56 & 4 & 8.5 & 2 & 2 & 0 \\
\hline 27 & & 2 & $\mathrm{~F}$ & $46-47$ & 57 & 6 & 9.3 & 1.5 & 2 & 0.5 \\
\hline 28 & 2 & & M & $35-36$ & 55 & 4 & 7.8 & 1.5 & 1.5 & 0 \\
\hline 29 & 2 & & $\mathrm{~F}$ & $35-36$ & 43 & 4 & 8 & 1.5 & 2 & 0.5 \\
\hline 30 & 2 & & M & $14-15$ & 61 & 2 & 10 & 2 & 4 & 2 \\
\hline 31 & 1 & & $\mathrm{~F}$ & 46 & 51 & 2 & 9.5 & 1.5 & 2 & 0.5 \\
\hline 32 & 3 & & M & $15-16-17$ & 57 & 3 & 8.2 & 2 & 3 & 1 \\
\hline 33 & 2 & & $\mathrm{~F}$ & $15-16$ & 62 & 3 & 9 & 2.5 & 4 & 1.5 \\
\hline 34 & 1 & & $\mathrm{~F}$ & 15 & 55 & 2 & 9 & 2 & 3.5 & 1.5 \\
\hline 35 & 2 & & M & $46-47$ & 41 & 3 & 9 & 1.5 & 2.5 & 1 \\
\hline \multirow{3}{*}{$\begin{array}{l}\text { Total } \\
\text { implants }\end{array}$} & 44 & 26 & & & & & & & & \\
\hline & & & & Mean & 60 & 4.61 & 9.41 & 1.81 & 2.76 & 0.96 \\
\hline & & & & St. Dev. & 10.526 & 2.358 & 1.149 & 0.365 & 0.721 & 0.599 \\
\hline
\end{tabular}

Patients are indicated as numbers. Implants A: Implants placed with one-stage approach (Group A); Implants B: implants placed with two-stage approach (Group B); Site: site of implant placement; VBG: vertical bone gain; HBW: horizontal bone width; FTB: flap thickness before GBR; FTA: flap thickness after GBR; STTG: soft tissues thickness gain; St. Dev.: standard deviation. 
Table 2. Implants placed with one-stage approach

\begin{tabular}{|c|c|c|c|c|c|c|}
\hline \multicolumn{2}{|c|}{ Implants Group A } & \multirow{2}{*}{ - VBG (mm) } & \multirow{2}{*}{ HBW $(\mathrm{mm})$} & \multirow{2}{*}{ FTB $(\mathrm{mm})$} & \multirow{2}{*}{ FTA $(m m)$} & \multirow{2}{*}{ STTG (mm) } \\
\hline Patients & Implants & & & & & \\
\hline 1 & 3 & 5.5 & 9.8 & 1.5 & 2 & 0.5 \\
\hline 3 & 3 & 5.5 & 10.5 & 2 & 2 & 0 \\
\hline 4 & 2 & 7 & 9.3 & 2 & 3 & 1 \\
\hline 5 & 2 & 6.5 & 8.8 & 1.5 & 2 & 0.5 \\
\hline 6 & 3 & 7 & 7.8 & 1.5 & 2 & 0.5 \\
\hline 8 & 2 & 4 & 8 & 2.5 & 3 & 0.5 \\
\hline 9 & 1 & 3 & 7.5 & 1.5 & 1.5 & 0.5 \\
\hline 12 & 2 & 4 & 8 & 2 & 3 & 1 \\
\hline 17 & 1 & 5 & 10.5 & 2.5 & 3 & 0.5 \\
\hline 19 & 2 & 4 & 8.8 & 1.5 & 3.5 & 2 \\
\hline 20 & 1 & 3 & 8.5 & 2 & 3 & 1 \\
\hline 21 & 2 & 2 & 9.5 & 2 & 3 & 1 \\
\hline 22 & 2 & 2 & 8.5 & 1.5 & 3 & 1.5 \\
\hline 24 & 1 & 5 & 9.5 & 1.5 & 3 & 1.5 \\
\hline 25 & 2 & 2 & 10 & 2 & 3.5 & 1.5 \\
\hline 28 & 2 & 4 & 7.8 & 1.5 & 1.5 & 0 \\
\hline 29 & 2 & 4 & 8 & 1.5 & 2 & 0.5 \\
\hline 30 & 2 & 2 & 10 & 2 & 4 & 2 \\
\hline 31 & 1 & 2 & 9.5 & 1.5 & 2 & 0.5 \\
\hline 32 & 3 & 3 & 8.2 & 2 & 3 & 1 \\
\hline 33 & 2 & 3 & 9 & 2.5 & 4 & 1.5 \\
\hline 34 & 1 & 2 & 9 & 2 & 3.5 & 1.5 \\
\hline 35 & 2 & 3 & 9 & 1.5 & 2.5 & 1 \\
\hline \multirow[t]{3}{*}{ Total implants } & 44 & & & & & \\
\hline & Mean & 3.85 & 8.93 & 1.83 & 2.74 & 0.93 \\
\hline & St. Dev. & 1.641 & 0.885 & 0.357 & 0.737 & 0.57 \\
\hline
\end{tabular}

Patients are indicated as numbers. VBG: Vertical bone gain; HBW: horizontal bone width; FTB: flap thickness before GBR; FTA: flap thickness after GBR; STTG: soft tissues thickness gain; St. Dev.: standard deviation.

OTB has been proposed as an alternative to PTFE because, in the case of exposure of the device to the oral environment, it seems to better protect the graft thanks to its non-permeability to oral fluids. At the same time, the absence of connective tissue penetration through the occlusive surface makes the barrier removal easier. In the present study, a double surface OTB was used. Its smooth outer surface limits bacterial adhesion and plaque-related inflammation if accidentally exposed to the oral cavity. The importance of smooth outer surface texture in preventing early bacterial colonization and biofilm formation was previously demonstrated on dental implants along with the fact that the mild micro-roughness of the inner surface clinically enhances the adhesion of the blood clot and the bone growth ${ }^{[21,22]}$. Furthermore, Yamada et al. ${ }^{[29]}$ and Ezirganl et al. ${ }^{[30]}$ demonstrated that barrier permeability is unnecessary to achieve successful bone regeneration. In previous studies, histological and histomorphometric analysis of human biopsies demonstrated the effectiveness of GBR by means of OTB, in combination with a composite allograft material ${ }^{[31]}$. The titanium barrier used in this study presents a thickness (120 microns) that allows easy contouring and adaptation to any ridge defect. These procedures can be performed outside the oral cavity on a printed STLM, which reduces the intra-surgical time and the risk of bacterial contamination, simplifying the clinician's work. In this case series, two accidental early exposures of the OTB to the oral environment occurred, but a good regenerative result was still achieved [Figure 4A-D]. The OTB's 
Table 3. Implants placed with two-stage approach

\begin{tabular}{|c|c|c|c|c|c|c|}
\hline \multicolumn{2}{|c|}{ Implants Group B } & \multirow{2}{*}{ - VBG (mm) } & \multirow{2}{*}{ HBW (mm) } & \multirow{2}{*}{ FTB (mm) } & \multirow{2}{*}{ FTA $(\mathrm{mm})$} & \multirow{2}{*}{ STTG (mm) } \\
\hline Patients & Implants & & & & & \\
\hline 2 & 3 & 5 & 10.5 & 1.5 & 2.5 & 1 \\
\hline 7 & 3 & 3 & 9.5 & 1 & 2.5 & 1.5 \\
\hline 10 & 2 & 4 & 10.5 & 1.5 & 2 & 0.5 \\
\hline 11 & 2 & 11 & 9.3 & 2.5 & 3.5 & 1 \\
\hline 13 & 2 & 6.5 & 11.5 & 2 & 4 & 2 \\
\hline 14 & 2 & 6.5 & 11.3 & 1.5 & 3.5 & 2 \\
\hline 15 & 2 & 9 & 11.5 & 2 & 2 & 0 \\
\hline 16 & 2 & 11 & 11.8 & 2 & 3 & 1 \\
\hline 18 & 2 & 4 & 10.5 & 2 & 3.5 & 1.5 \\
\hline 23 & 2 & 3 & 9.5 & 2 & 3 & 1 \\
\hline 26 & 2 & 4 & 8.5 & 2 & 2 & 0 \\
\hline 27 & 2 & 6 & 9.3 & 1.5 & 2 & 0.5 \\
\hline \multirow[t]{3}{*}{ Total implants } & 26 & & & & & \\
\hline & Mean & 6.08 & 10.31 & 1.79 & 2.79 & 1 \\
\hline & St. Dev. & 2.867 & 1.077 & 0.396 & 0.722 & 0.674 \\
\hline
\end{tabular}

Patients are indicated as numbers. VBG: Vertical bone gain; HBW: horizontal bone width; FTB: flap thickness before GBR; FTA: flap thickness after GBR; STTG: soft tissues thickness gain; St. Dev.: standard deviation.

exposure, if perfectly immobilized with screws and cleaned by the patient, does not appear to compromise the clinical outcome, providing predictable results even in case of accidental exposure ${ }^{[31]}$.

This study also suggests a novel approach to immediate soft-tissue augmentation. In six cases, where the free gingival graft was necessary, this was performed at the same time as the barrier removal. The rationale for this approach is to exploit the potential of the white connective layer, which forms below the OTB and seems to represent a good and stable substrate for both revascularization and maturation of the free gingival graft [Figure 6A-D]. This immediate soft-tissue augmentation can theoretically improve the future crestal bone stability [Figure $7 \mathrm{C}$ and $\mathrm{D}$ ], considering that a vertical soft tissue thickness between 3 and $4 \mathrm{~mm}$ has been demonstrated to be important for the crestal bone stability around implants through the years ${ }^{[32]}$. Moreover, for the majority (94.3\%) of cases in this study, a spontaneous increase of STT was observed at the second surgical stage. This phenomenon, which could improve the volumetric stability of the regenerated bone around the implants, can be attributed to titanium biocompatibility and occlusivity of the device, which does not hinder the flap mobility and spontaneously increases the thickness of soft tissues over the OTB. Moreover, the flap passivation techniques are probably able to promote blood clot formation above the OTB, which leads to connective tissue increase and consequently to FT augmentation. It is difficult to compare the present promising results with the currently available data in the literature because there is a lack of studies on the increase of FT following GBR procedures.

In conclusion, GBR with OTB can be a viable option in the treatment of atrophic jaws. Within all the limitations of this study, we showed that the use of an OTB can lead to hard tissue augmentation even in the case of accidental exposure, as long as it has been properly fixed to the residual bone. Although OTB preshaping on an SLTM simplifies the surgical procedure, the GBR generally requires expert surgeons. While in the present study the choice of simultaneous or delayed implant placement was randomly made by the operator, we recommend a more cautious approach, advising, in the case of vertical bone augmentations $\geq 4 \mathrm{~mm}$, a staged implant placement. The delayed implant placement allows planning a more precise 
prosthetic-driven implant placement, improving crestal bone stability over time $\mathrm{e}^{[32,33]}$. In almost all cases, a spontaneous FT increase was observed at the second surgical stage. This phenomenon could be attributed to the biocompatibility and occlusivity of the OTB. These outcomes suggest the potential of this technique in augmenting hard and soft tissue in vertical defects and encourage further prospective studies aimed at confirming its effectiveness.

\section{DECLARATIONS}

\section{Authors' contributions}

Gave substantial contributions to the study's conception and performed the clinical cases and data acquisition: Perret $\mathrm{F}$

Provided for the bibliographic review: Aimetti M

Performed both data analysis and interpretation: Andreasi Bassi M

\section{Availability of data and materials}

Not applicable.

\section{Financial support and sponsorship}

None.

\section{Conflicts of interest}

All authors declared that there are no conflicts of interest.

\section{Ethical approval and consent to participate}

The study was performed in compliance with good clinical practice and the WMA Declaration of Helsinki for ethical principles in medical research involving human subjects (amended by the 64th WMA General Assembly, Fortaleza, Brazil, October 2013). Since a simple data collection was performed before and during the surgeries, the presence of an ethics committee was not required.

\section{Consent for publication}

Informed consent was obtained from patients regarding the treatment protocols and the publication of related clinical pictures.

\section{Copyright}

(C) The Author(s) 2022.

\section{REFERENCES}

1. Lee JS, Jung JS, Im GI, Kim BS, Cho KS, Kim CS. Ridge regeneration of damaged extraction sockets using rhBMP-2: an experimental study in canine. J Clin Periodontol 2015;42:678-87. DOI PubMed

2. Araújo MG, Lindhe J. Ridge preservation with the use of Bio-Oss collagen: a 6-month study in the dog. Clin Oral Implants Res 2009;20:433-40. DOI PubMed

3. Esposito M, Grusovin MG, Felice P, Karatzopoulos G, Worthington HV, Coulthard P. Interventions for replacing missing teeth: horizontal and vertical bone augmentation techniques for dental implant treatment. Cochrane Database Syst Rev 2009;2009:CD003607. DOI PubMed PMC

4. Aghaloo TL, Moy PK. Which hard tissue augmentation techniques are the most successful in fur-nishing bony support for implant placement? Int J Oral Maxillofac Implants 2007;22 Suppl:49-70. PubMed

5. Dahlin C, Linde A, Gottlow J, Nyman S. Healing of bone defects by guided tissue regeneration. Plast Reconstr Surg 1988;81:672-6. DOI PubMed

6. Schmid J, Hämmerle CH, Olah AJ, Lang NP. Membrane permeability is unnecessary for guided generation of new bone. An experimental study in the rabbit. Clin Oral Implants Res 1994;5:125-30. DOI PubMed

7. Van Steenberghe D, Johansson C, Quirynen M, Molly L, Albrektsson T, Naert I. Bone augmentation by means of a stiff occlusive titanium barrier. Clin Oral Implants Res 2003;14:63-71. DOI PubMed

8. Wang HL, Boyapati L. "PASS" principles for predictable bone regeneration. Implant Dent 2006;15:8-17. DOI PubMed

9. Simion M, Jovanovic SA, Tinti C, Benfenati SP. Long-term evaluation of osseointegrated implants inserted at the time or after vertical 
ridge augmentation. A retrospective study on 123 implants with 1-5 year follow-up. Clin Oral Implants Res 2001;12:35-45. DOI PubMed

10. Urban IA, Montero E, Monje A, Sanz-Sánchez I. Effectiveness of vertical ridge augmentation interventions: a systematic review and meta-analysis. J Clin Periodontol 2019;46 Suppl 21:319-39. DOI PubMed

11. Buser D, Ingimarsson S, Dula K, Lussi A, Hirt HP, Belser UC. Long-term stability of osseointe-grated implants in augmented bone: a 5-year prospective study in partially edentulous patients. Int J Periodontics Restorative Dent 2002;22:109-17. PubMed

12. De Marco AC, Jardini MA, Lima LP. Revascularization of autogenous block grafts with or without an e-PTFE membrane. Int J Oral Maxillofac Implants 2005;20:867-74. PubMed

13. Jardini MA, De Marco AC, Lima LA. Early healing pattern of autogenous bone grafts with and without e-PTFE membranes: a histomorphometric study in rats. Oral Surg Oral Med Oral Pathol Oral Radiol Endod 2005;100:666-73. DOI PubMed

14. Carbonell JM, Martín IS, Santos A, Pujol A, Sanz-Moliner JD, Nart J. High-density polytetrafluoroethylene membranes in guided bone and tissue regeneration procedures: a literature review. Int J Oral Maxillofac Surg 2014;43:75-84. DOI PubMed

15. Perret F, Romano F, Ferrarotti F, Aimetti M. Occlusive titanium barrier for immediate bone augmentation of severely resorbed alveolar sockets with secondary soft tissue healing: a 2-year case series. Int J Periodontics Restorative Dent 2019;39:97-105. DOI PubMed

16. Lundgren D, Lundgren AK, Sennerby L, Nyman S. Augmentation of intramembraneous bone beyond the skeletal envelope using an occlusive titanium barrier. An experimental study in the rabbit. Clin Oral Implants Res 1995;6:67-72. DOI PubMed

17. Molly L, Quirynen M, Michiels K, van Steenberghe D. Comparison between jaw bone augmentation by means of a stiff occlusive titanium membrane or an autologous hip graft: a retrospective clinical assessment. Clin Oral Implants Res 2006;17:481-7. DOI PubMed

18. Andreasi Bassi M, Andrisani C, Lopez MA, Gaudio RM, Lombardo L, Lauritano D. Guided bone regeneration in distal mandibular atrophy by means of a pre-formed titanium foil: a case series. J Biol Regul Homeost Agents 2016;30:61-8. PubMed

19. Andreasi Bassi M, Andrisani C, Lopez MA, Gaudio RM, Lombardo L, Carinci F. Guided bone regeneration by means of a preformed titanium foil: a case of severe atrophy of edentulous posterior mandible. J Biol Regul Homeost Agents 2016;30:35-41. PubMed

20. Rakhmatia YD, Ayukawa Y, Furuhashi A, Koyano K. Current barrier membranes: titanium mesh and other membranes for guided bone regeneration in dental applications. J Prosthodont Res 2013;57:3-14. DOI PubMed

21. Fontana F, Maschera E, Rocchietta I, Simion M. Clinical classification of complications in guid-ed bone regeneration procedures by means of a nonresorbable membrane. Int J Periodontics Restorative Dent 2011;31:265-73. PubMed

22. Lundgren AK, Lundgren D, Wennerberg A, Hämmerle CH, Nyman S. Influence of surface roughness of barrier walls on guided bone augmentation: experimental study in rabbits. Clin Implant Dent Relat Res 1999;1:41-8. DOI PubMed

23. Jang YS, Moon SH, Nguyen TT, et al. In vivo bone regeneration by differently designed titanium membrane with or without surface treatment: a study in rat calvarial defects. J Tissue Eng 2019;10:2041731419831466. DOI PubMed PMC

24. Tinti C, Parma-Benfenati S, Polizzi G. Vertical ridge augmentation: what is the limit? Int J Peri-odontics Restorative Dent 1996;16:220-9. PubMed

25. Urban IA, Monje A, Lozada J, Wang HL. Principles for vertical ridge augmentation in the atrophic posterior mandible: a technical review. Int J Periodontics Restorative Dent 2017;37:639-45. DOI PubMed

26. Tinti C, Parma-Benfenati S. Vertical ridge augmentation: surgical protocol and retrospective evaluation of 48 consecutively inserted implants. Int J Periodontics Restorative Dent 1998;18:434-43. PubMed

27. Ronda M, Stacchi C. A novel approach for the coronal advancement of the buccal flap. Int J Periodontics Restorative Dent 2015;35:795-801. DOI PubMed

28. Andreasi Bassi M, Lopez MA, Confalone L, Carinci F. Hydraulic sinus lift technique in future site development: clinical and histomorphometric analysis of human biopsies. Implant Dent 2015;24:117-24. DOI PubMed

29. Yamada Y, Sato S, Yagi H, Ujiie H, Ezawa S, Ito K. Correlation in the densities of augmented and existing bone in guided bone augmentation. Clin Oral Implants Res 2012;23:837-45. DOI PubMed

30. Ezirganlı Ş, Polat S, Barış E, Tatar İ, Çelik HH. Comparative investigation of the effects of different materials used with a titanium barrier on new bone formation. Clin Oral Implants Res 2013;24:312-9. DOI PubMed

31. Andreasi Bassi M, Andrisani C, Lico S, Ormanier Z, Ottria L, Gargari M. Guided bone regeneration via a preformed titanium foil: clinical, histological and histomorphometric outcome of a case series. Oral Implantol (Rome) 2016;9:164-74. DOI

32. Linkevicius T, Apse P, Grybauskas S, Puisys A. The influence of soft tissue thickness on crestal bone changes around implants: a 1year prospective controlled clinical trial. Int J Oral Maxillofac Implants 2009;24:712-9. PubMed

33. Linkevicius T, Puisys A, Steigmann M, Vindasiute E, Linkeviciene L. Influence of vertical soft tissue thickness on crestal bone changes around implants with platform switching: a comparative clinical study. Clin Implant Dent Relat Res 2015;17:1228-36. DOI PubMed 